Symposium contribution

\title{
"Islands of Qualities in an Ocean of Quantification": A Conversation with Wendy Espeland and Michael Sauder
}

\author{
José Ossandón, Wendy Espeland and Michael Sauder
}

\begin{abstract}
In this interview, Wendy Espeland and Michael Sauder both reflect on their work on rankings, reactivity and commensuration, and think about the implication their sociological work could have on the practices of those dealing with rankings and their reactive effects.
\end{abstract}

Keywords: valuation; rankings; reactivity; higher education; management; commensuration

José Ossandón is an Associate Professor at the Department of Organization, Copenhagen Business School.

Wendy N. Espeland is a Professor at the Department of Sociology, Northwestern

University.

Michael Sauder is a Professor at the Department of Sociology and Criminology,

University of Iowa.

(C) 2021 The authors (cc) BY This work is licensed under a Creative Commons Attribution 4.0 International License.

https://doi.org/10.3384/VS.2001-5992.2021.8.2.103-121

Hosted by Linköping University Electronic press

http://valuationstudies.liu.se 


\section{Valuation Studies}

\section{Introduction}

José Ossandón: First, let me briefly introduce the problem that motivates this interview and this correspondence more generally.

Valuation studies can be characterized in terms of a productive heuristic. Social researchers do not only study the values behind valuation - ideologies, culture - they can study valuation practices the techniques, knowledge and devices, and how these practices and devices impact organizations and other social processes (e.g. Stark 2011). What the vast amount of studies in the area - including the many papers in the journal Valuation Studies - demonstrated is that there were so much social researchers could learn from valuation practices. This conversation expects to reflect upon whether there is a possibility of reciprocity in this exchange. Can practitioners - those involved in the everyday work of running organizations that are affected by new or old powerful forms of valuation - learn from valuation studies?

To do that, I proposed to you and the other participants a kind of scenario. We will not discuss valuation and management in general. We will discuss an area that we all know very well, namely, the management and organization of research institutions, in particular universities. This is in fact very important. What your work demonstrates so well it is that valuation infrastructures - such as rankings - matter greatly. They can radically transform how universities are managed and in the end what counts as quality. We also know that these are not unidirectional processes, and that how institutions deal with rankings changes so much in different contexts and in different organizations or even across departments in the same institution.

The overall question is: Does the knowledge produced in valuation studies have something to say to those involved in managing research quality in universities?

I know - and you have been very clear in our previous communication about this - that this is not something you have already researched, and that this conversation takes you (and the others too) into tentative territory. I should clarify though that the goal here is not a fully fledged management theory. In fact, a key part of the problem does not seem to be a lack of management theories in universities but rather an excess. The conversation aims to be humbler and more concrete. A way to formulate what we are trying to do here is not to assume that we should tell people how to do their job, but, that, perhaps, we could think about how our research could help those that are already troubled to think about their troubles differently. 
That's the general framework. More practically, what we have done so far is that I wrote a short text as provocation; we then received responses from Kristian Kreiner and Christine Musselin, and then the last contribution in the correspondence is this conversation. I have prepared six questions or topics on which to talk to you. The first and second are more about contextualization; they are about your work on rankings more generally, and the questions afterward are more directed at addressing the problem of the conversation.

\section{Sociologists of quantification}

How did you realize that you could make rankings - and university rankings in particular - an object of sociological study? How did you become sociologists of rankings?

Wendy Espeland: I had been interested in quantification for a long time based on prior work. I was looking for a new object, and I was talking to a colleague who was talking to me about that he happened to be a former dean of a law school. He was mentioning how much rankings were affecting law schools. That struck me as a really interesting example; partly because at that point rankings were relatively new, so it might be possible to capture the before and after effect by talking to people who had long tenure. So that seemed like another appealing aspect of rankings. But really it was sort of just conversations with colleagues that helped me to latch on to this particular object.

Michael Sauder: Wendy had this long-term interest in commensuration, and rankings are this clear example of commensuration. I was studying status processes and hierarchies. Rankings were this nice example of the formal status structure that had taken the place of an informal status structure. So, it really resonated with me as soon as we started talking about rankings. Then, once we started to study rankings, it really took on a life of its own. I think because of the surprising effects that rankings have on institutions and the breadth of those effects, then the richness of all these social processes intersecting became very clear. There are so many things going on at once.

José Ossandón: Today, we take for granted that what you study counts as sociology. But, was that what you had to fight for to be accepted by your colleagues and in journals? Was it obvious that rankings could be a sociological object of analysis? 


\section{Valuation Studies}

Wendy Espeland: When I first became interested in quantification most people in sociology were interested in how to do it better rather than examining it as a social phenomenon or object. Within sociology, there weren't very many people who were thinking in those terms. There was some early work on official statistics that was interesting, but I mostly found colleagues were outside of my discipline in either the history of science, or in accounting, and science studies. Now, I think that there is an emerging field called sociology of quantification that I think makes it a less unusual topic to investigate. But I think initially, it took some work to convince people that quantification in general could be an object of study. But because people experienced rankings so directly as academics, it wasn't very hard to convince them that this was interesting. What was challenging was to convince them to let us study them [laughing] because they were very anxious about the effects of being studied. So, there were a number of people that we approached who told us that "oh, this is fantastic work, but no, you can't study our law school". The challenge was less, later on, how to convince people that this was an interesting object rather than to let us study them, which I suppose isn't surprising [laughing].

Michael Sauder: I agree that the study of rankings was something that people found interesting because they were affected by them. Everybody thought it was a very compelling topic from the beginning. Although, I do remember us having a lot of trouble with the first paper, the reactivity paper, in terms of finding out how to frame it for a general sociological audience.

Wendy Espeland: That's right.

Michael Sauder: We had all these different ideas, but were struggling between the sociology and science, and organizations, and even some interactional theoretical ideas. How should we frame this to communicate all this great data we have to this audience in a way that they will see it as sociology, or whatever type of sociology it is? We struggled with that. I think we worked it out in the end. I feel lucky, because I feel like we could have probably gone in a different direction and it would not have been as effective. It would be much easier now because there's a quantification literature that we could speak to, which did not exist in sociology at that point.

\section{Rankings and reactivity}

José Ossandón: For many readers, the first encounter with your coauthored work was through your "Rankings and Reactivity" paper published in the American Journal of Sociology in 2007. There you inspect the impact of a specific ranking, the U.S. News and World 
Report ranking of law schools, on the way law schools are actually managed. You proposed a theoretical model based on one key concept, "reactivity" and two main mechanisms "self-fulfilling prophecies" and "commensuration". The second question is what would you say is the current status of this model, do you still use it, have you added further mechanisms or new ways of thinking these processes in your more recent work? How do you see this quite well established paper and model thinking about the reactivity of rankings today?

Wendy Espeland: I can suggest one observation, which is that I think the reactivity model is still effective and capturing kind of the interactive effects. But I think it underplays the role that quantification takes in the constitutive effects of numbers and helping to produce the object that is being measured. I think maybe that aspect should be incorporated into the model more clearly, i.e., the way that numbers produce certain kinds of relationships that then become objects of measurements.

Michael Sauder: It is interesting to use the word model. In a way, I don't think of it as a model. I think of these as concepts. You have me thinking back to when we started. There were a lot of directions it could go. We were trying to find a way to talk about it and to find the most powerful mechanisms that we saw that were emerging from the data. To me these concepts still work well in new situations, but it does not mean that there aren't more concepts or other directions to go. I have been thinking more lately about the institutionalization of rankings, so almost like the second stage of this. We were documenting a case that was toward the beginning of when rankings were introduced and showing how people were reacting and adjusting to this new system. It is worth asking, now that rankings are part of the educational field, how have their effects been written into organizations after all this time? How do people become accustomed to them? Are they so powerfully institutionalized that they are hard to question at this point? There is a lot of new work being done in this direction. Assuming that rankings are here to stay, what are the relationships between the rankers and the people being ranked? And how are internal dynamics changed because of this?

\section{Can sociologists of ranking give advice to university managers?}

José Ossandón: Your book Engines of Anxiety (Espeland and Sauder 2016) narrates how a ranking impacted on all the different layers of the law schools in the US. You have chapters on prospective students, 


\section{Valuation Studies}

admissions, career services, and the deans. In relation to our conversation here, a key chapter is the one about the deans. What we as readers get through your description is a picture of the deans you interviewed as being very troubled with the situation in which they found themselves. As Christine Musselin (2018), in her previous work on European universities shows, there seems to be an important professional transition, from the dean as an academic peer with more authority, to deans as professionalized managers. In this new context, the success and quality of the dean's job seems to be increasingly seen in terms of the relative position of the institution they manage in competitive and relative rankings.

In your case, everyone seems to care a lot. Students care about the position of their institution; you narrate these very strange situations where students will even sue institutions if rankings go down, as if their investment in human capital were at stake. You show also how donors care, and that even faculty seems to care, for instance, when choosing their jobs. The deans however seem to have a clear picture of the paradoxical situation in which they find themselves. They know there is a basic tension between the ranking position and what the ranking is supposed to measure - the quality of their institution. I found that was very interesting because you show them as reflexive actors that seem to be quite troubled with the situation in which they find themselves. So, on the one hand, they seem to understand that their school's position is not about its quality. There is discordance between the ranking and what it is supposed to measure. However, they seem to assume too that the power of the ranking is something they cannot fight against, and that they have to act as if this were the actual measure and target of their task. It is a dramatic position. The question is: what do you tell the deans? Have you presented your work to them? What do you say when they tell you: "you describe perfectly our troubles, but what should we do about them now?"?

Wendy Espeland: That is, of course, the million-dollar question, so thank you so much [All laughing]. The deans did initially try resisting in various ways and those were very ineffective. The reason they were ineffective is because they could not be gatekeepers over who is applying and who is deciding where to go to law school. What we found was this weird reversal of power where in some ways the least powerful people, who are the applicants and the potential students, their decisions become consequential over time because they affect the rankings. Then the deans are forced to pay attention to that. They have always paid attention to that, but it has never been quite as consequential as when this becomes a part of the ranking machinery. So, what we tell deans is that at this point, we don't see any signs of the rankings being disrupted in any meaningful way. At some point, 
that might happen and the whole thing will collapse under the weight of incessant evaluation. At that point, we think that they will have to live with that for a long time. Their job is to do the best they can with the rankings, while trying to continue to point out the flaws and how they are being evaluated.

Michael Sauder: One thing that comes to mind is that the paradox of being trapped by and understanding the limitations of the rankings, but being forced to do something about them is real. I think when we talked to people afterwards - and there could be a selection problem here - people really thought that this was accurate. I do wonder, and I am curious now if that kind of caught in-between feeling has diminished over time because of the acceptance of rankings. A portion of the deans we talked to when we did the interviews for the study knew or were familiar with the world both before rankings and after rankings. They were kind of adjusting to this. Now, I think when deans are hired, they just know that rankings are an important part of that world. They may be more pragmatic about this as something they have to deal with. They may not question the rankings as much. That is an empirical question to ask.

José Ossandón: Is that what you meant before with "institutionalization"? How it has changed in this very short period; that it has become more taken for granted.

Michael Sauder: We saw this more with the associate deans, I think, during our study, where a lot of them experienced the pressure of producing numbers at that time because they actually had to gather the career services data and gather the admissions data. They knew colleagues who had been fired because their numbers weren't high enough. At that point, we could really see in that job that people who were good at managing the numbers were taking over these positions. You could glimpse that transition, that institutionalization at that point. I wonder if that institutionalization just increased over time. Numbers are just taken for granted now. We don't even imagine what the alternative would be.

Wendy Espeland: One thing that we were told by a number of people is that when deans are being interviewed for the job, they are all asked what they will do either explicitly about the rankings or implicitly about the reputation of the law school. So, most people who come into the job understand that this is a part of it. They were asked to have a plan for that when they were being interviewed. That also suggests further institutionalization. There may be less angst now in terms of 


\section{Valuation Studies}

how naturalized the numbers have become. I still suspect that people generally feel that these are not the best measures. A lot of energy is going into producing the material to be ranked. I think sometimes that people feel that it is time they should be spending on other things that are more valuable to the institution. So that is a different form of angst.

José Ossandón: What would you do if you were a dean of a law school? [All laughing].

Michael Sauder: I don't know how to answer that question. I really appreciate the difficulty of their position. I would understand the limitations of these numbers, but it would probably depend on the particular situation you were in. How much you had to tailor your responses to numbers as opposed to the other concerns that are going on. So, it might be how much pressure you are getting from the outside. I guess I would try to convince my constituency about the limitations of the numbers and try to teach them how to understand the numbers. Like a change in one rank isn't meaningful. Like a change in ten ranks may be meaningful. So, maybe take the focus off the precise distinctions of the numbers. Try to take that message to all of your constituents. If they don't believe that, then you are in the same situation as the deans were in before. I mean, you are stuck between ... you probably should not take that job [all laughing].

José Ossandón: You use this word anxiety. Reading your book again made me think about Karpik's book (2010). He really stresses the particularities of what he calls singularities, unique goods, and how with singularities, people can use devices that help to make them comparable, but that this shouldn't be confused with calculation. When I was reading the deans' chapter again, I was thinking that they feel that anxiety. They seem to feel that it is not only that their work will be assessed in terms of this going up or down, but that, in the end, the ranking has very little to do with whether their law school is any good. There seems to be an anxiety about whether this has taken them in a completely wrong direction, in a way. Do you think that anxiety has to do with that?

Wendy Espeland: Yes, I think that is true. One source - there are multiple sources of anxiety - is your sense of professional judgment being compromised. You have the sense that you might know what is best for the school, but you can't do it because you are forced to be accountable to this algorithm that you didn't construct. That is one source of anxiety. Another huge source of anxiety is the sort of competition that emerges as a result of these devices that make everyone in a very precise relationship with everyone else. Even if you 
are doing well, if other people around you are doing something differently, including maybe something you may not think appropriate, if it makes them look better at the rankings, then you are being punished. It is the zero-sum quality of the relationship, and the anxiety about "fear of falling", that you don't really control what is happening to your institution in the ranking. You do the best you can, but it all depends on the relationship with all these other schools. That is another prominent source of anxiety; that extends to being anxious about what kinds of practices are being incentivized that you may think are inappropriate or even morally repugnant.

Michael Sauder: Your question also makes me think about something I don't think we have written directly about, but from our interviews you can see how deans and other administrators are frustrated by the idea that they know the strengths of their institution; they know all of these great things their school does, the richness of their activities. But it is very frustrating to have all of that richness reduced to a single number, and have people focus on that single number. I like the comparison with Karpik (2010) because there is a tension there ... they actually want people to value universities in different ways, and to understand that there are different ways to value universities. But they really do feel like their hands are tied and that this one form of evaluation has drawn all of the attention from a lot of different audiences. And it limits their ability to convincingly argue about what is unique and special about their institution. They all had a lot to say about what was unique and special about their institution.

\section{Assessing researchers}

José Ossandón: My next question is about the case Christine Musselin (2021) shared with us. Christine's text is quite unique, I think. It is a first-person testimony of her practice of assessing quality as her institution's vice-president. This is less about assessing a full institution (like in your research) but assessing individual researchers. What we get from her description is a sense of valuing as a series of discrete moments, with many decisions and conflicts that could go in many different directions. She uses some of your concepts, like "commensuration", to name these moments. Valuation appears like a process where each moment can go in so many directions. How do you relate to her description and how do you navigate your own role in decisions regarding the assessments of researchers, hiring and colleagues? 


\section{Valuation Studies}

Wendy Espeland: One of the things that I really appreciated about Christine's essay was the emphasis that she placed on categorization. How one of the fundamental decisions that had to be made were what are the categories you have to use and what are the domains you are going to incorporate? If I remember, one of the categorizations had to do with professors versus researchers, and they decided to create a kind of blending of those. I see a direct parallel in the ranking research in the sense that when USN created the algorithm there were a number of different kinds of law schools but the decision was made to use one algorithm to evaluate everyone. Instead of selecting out law schools that had different missions, like, for example law scholars that were oriented toward public service or that were oriented toward including people entering into the profession who had been marginalized in the past. Those distinctive missions weren't incorporated into the algorithm, so they were punished for doing a good job in what they intended to do. For me that is highlighted as a parallel with Musselin's emphasis on the role that categorization plays. So, what is a law school? What does it mean to be a professor or a researcher? This is really important, the kind of distinctions that were made. So, the categorization effect is really, really important.

Michael Sauder: I agree. Who is in and who is out? Who counts and who doesn't? These are great questions that the piece raises. I was thinking about the second half of your question about, you know, what happens when you participate in these projects? That's an interesting question. I really did like your offended native, anxious scholars, and useless practitioners (Ossandón 2021). I could relate to all of those. One of the things that these two pieces - your case and Christine's piece - made me think about was the pressure to be pragmatic in all of these stages of evaluation. Because when I've been asked by someone, not very often, at my university about the rankings, you could tell that there is a lot of pressure to make this decision efficiently. I should say that this applies to almost any evaluation or any time we use numbers. But I feel that pressure too. Like I could open up boxes for them and say "look, this is a problem, this is a problem, and this is a problem", but nobody wants that because nothing would get done [all laughing]. You feel pressure in the room to be pragmatic and say these are the rules of the game, and within these rules here's the best that we can do. But you can also tell that the pressure extends outward and upward; because everyone is very busy and wants to get this done. One of the striking things is how numbers are such a great vehicle for this pragmatism. I mean, you can say: "look, we just want to know about this number", and the whole conversation is just about that number now. We don't open up the box to see all the little parts that constitute that number. I think one of the things that rankings and other sources of quantitative evaluations do is 
that they create this kind of momentum of how to make decisions, and what the rules of the decisions should be. Unless you have a lot of time and extra resources you are not going to question how these things are made. You are just going to orient the questions in certain ways. You are going to feel that pressure to go along with those rules as they were set.

José Ossandón: Do you find any difference across disciplines? You work in departments of sociology. Are sociology departments, in your experience, more reflexive when managing themselves, for example, about identifying limits or situations that cannot be quantified, or of reintroducing these kinds of issues at the moment of managing researchers?

Wendy Espeland: One place where you do see more attention to qualitative dimensions that may be a resistance to simplifying through numbers is in two really big decisions. One is hiring, and the other is tenure. In the United States, tenure is this very fateful decision and institutions and departments invest a lot of resources in that. So, there is a lot of deliberation that goes on. There's a lot of talk and there's readings of articles that goes on. So, when people are in the conversations in a department, you talk about quality of the work as well as the volume of the work. When someone's decision is going up the chain, inside the university you also send for outside letters. The outside letters that interpret the record for you, those are very fateful. So, tenure strikes me as a kind of decision that is recognized as being crucial for someone's career. There is an effort to include qualitative as well as quantitative information. Even though they may require you to include citation counts, for example, or you may have to refer to the $b$ index, which evaluates your productivity, there is still room for deliberation about the quality of the work.

That happens too when hiring. In Kristian's piece (Kreiner 2021), I was really taken with this piece, about how sometimes the justification is what is important rather than the actual decision. You make a decision and you justify it afterwards. That can happen in hiring decisions: "I like someone, therefore I am going to make a good argument for them", or "I don't want someone to work here, so can I find a rationale?". There is still room for deliberation and trying to convince your colleagues to think differently about something. That's a place where I feel more hopeful about the effort to kind of include other arguments about quality in addition to just the numbers. 


\section{Valuation Studies}

José Ossandón: Does it change with different disciplines? For instance, it is quite new that here we at Copenhagen Business School (CBS) use tenure-track, and we have very different systems depending on the departments. In the more economics-oriented departments, decision is much more automatic, algorithmic like (e.g., if you publish in these $\mathrm{X}$ journals you will be qualified). In our department (after many discussions, I could have written about this process too for this correspondence!), we decided to have a less algorithmic type of decision. In your experience, do you see what you are describing for hiring as a more general practice, or is it a disciplinary issue? For example, it is more qualitative in sociology departments whereas in other departments it is a more algorithmic process.

Wendy Espeland: It may well be different in different disciplines. I have heard from administrators that economics again seems to be a discipline that has a clear sense of quality. You know, there is a shared theoretical paradigm, shared sense of understanding of what are the good journals. Perhaps it is more automatic in those fields. But, even among the deliberation there is still the importance of the status of the journal or where the article was published. That certainly plays into how people evaluate work. But you could also make an argument about why something in an obscure journal is still good. It may not carry the day, but at least there is a potential. I am not sure how that varies across disciplines as Michel Lamont (2009) has shown.

Michael Sauder: I think it is a great conversation. I love the points that are being made. It strikes me that it has great potential for empirical investigation. It is an empirical question at this point. I like how Wendy is describing what I see as these kinds of islands of qualitative evaluation in this process. So, I think those spaces may be bigger in some locations than others, but I have to imagine that they take place even in the economics department that is driven by the numbers. At some point, people are discussing the weight of this, finding it is so big that it should count more than a level 3 article or something. You would have to empirically study how and where that qualitative evaluation takes place. Then, what would be interesting to study would be the translation process that goes on. Your department has this discussion about the qualitative merits of a person's tenure record. You use your judgment and make a decision, but then how is that decision translated into the next level of hierarchy? Do you have to use numbers then somehow to take your case to the next level of judgment, or how do you translate your expertise or decision to that next level? I think that would be a great thing to study at the university. 


\section{Managing quality}

José Ossandón: The other example we have is the example here at CBS. This is a different type of situation in which we as researchers participate in the management of quality in universities. In my short text in this correspondence, I tell the story of my participation in the task force to implement a list of preferred journals in the department where I work (Ossandón 2021). The situation has different aspects. The need comes from the dean of research, the boss of our head of department. We assume that to him quality equals research published in journals assessed high in the Academic Journal Guide published by the UK's Chartered Association of Business Schools.

What I describe in my notes is my experience. I felt that because of the work you and others have developed, I had tools to describe what was going on and the possible consequences. For example, lists do not describe quality, they are devices useful to those who have to decide without knowing enough to assess specific pieces of research; for instance, librarians or deans who come from different disciplines, but, once implemented, they can change how quality is accounted for. For example, we might face a future where the quality of our work will be equated with the tier of the journal in which they are published without caring about the papers themselves. Judgment is externalized. At the same time, I felt that I was not very useful. I was complaining a lot and everyone got tired of me complaining about it.

In his response, Kreiner (2021) expands on the implications of the assumption that quality is what is published in journals with high rankings. As he puts it, this creates the illusion that we can know the quality of someone's work without reading it. He also decided to use a particular tone - to those that work with him, we could call it the Kreiner tone - that is, he writes his contribution as a polemic addressed to our managers and oriented to affect their view on the processes.

How do you react to this case? How would you deal with the confusion between journal quality and the quality of research output? What would you do in the situation of our head of department? Actually, something I have always found amazing when I talk with colleagues that practice sociology in the US is how much they trust in two journals, AJS and ASR. It is not a list, like in the example, but there seems to be a common assumption that good sociology is what is published in these two journals, and if it appears elsewhere in the world is it likely less good? The question is how do you deal with this 


\section{Valuation Studies}

tension, the quality of the work and the quality of the output, and what would you do in my head of department's situation?

Michael Sauder: I don't know. That is a hard question [all laughing]. One thing that comes to mind is just how self-reinforcing this process can be. Once it starts and you start associating quality with journals then that becomes institutionalized. I don't know how you get out of that cycle. I am sorry, it is a hard question. I was on a university committee looking not only at social sciences, but also at humanities and natural sciences and evaluating these cases against each other. All I could think about was - aside from journal quality - if I am assessing a mathematician or a biologist, it is hard to do. I can't assess the quality of the work except from the descriptions given by their department chairs. The quality of the journals - the farther away you get, the harder it gets to understand and compare those qualities. In one way, I am stuck. I am not sure how to get out of this. It makes me think about the translation issue again. If you are in a position to make a qualitative judgment and say that this article which was published in a small journal is of high quality and of high impact, how do you translate that to audiences who don't have expertise in that area?

Wendy Espeland: That is a place for letters or for other assessments of quality that could help make the case. Someone could say this is published in this obscure journal, but it is a really breathtaking or original piece of work that is gaining lots of attention by specialists, or something like that. But I agree with Kristian Kreiner that this circularity of these processes is the most insidious in the sense that if everyone treats it as so, it becomes so. Then we are stuck with the so [laughing]. But I suppose we could make a pledge to have leading scholars try to publish in other locations as a way to establish the legitimacy of doing so.

José Ossandón: I was thinking in terms of what Michael was saying. I don't know if you have read Daniel Beunza's recent book (2019). It is ethnography of management in finance and the impact of risk-based modelling in this context. One of the things I took from his book is that how elevated you can get in the hierarchy to decide about someone else's quality is also a managerial decision. The farther you go, the more abstract your decision is, and the farther you are from the actual work. Beunza advocates what he calls "proximate control". Maybe, it is not that different in institutions like universities. Maybe, at a place like CBS the dean is simply too far in the organization to assess research quality produced in the departments. A possible answer could be to delegate this decision to managers a level below in the organization, those who are closer and can actually understand the 
work that is assessed. How to deal with this decision is a management problem.

Wendy Espeland: The [Peter] Miller and [Nikolas] Rose concept of governing at a distance (Miller and Rose 1990) - that is what quantification makes possible - governing from a distance. Maybe you are right. We should limit the distance at which someone is allowed to govern. So many things go back to James G. March and Johan P. Olsen (2010). The idea of uncertainty absorption and the sort of complexity of evaluation in all of the decisions that Christine Musselin is talking about become more obscure as decisions move up the hierarchy. Things look much more factual and much more certain the further they are away from those who produce them. That would be another argument for sort of limiting the distance at which people judge, but of course the overwhelming problem with that is that those are not the people who are going to give up discretion. They are not going to say: "You are right, I am too far away as a dean to make this decision, so I am going to let you do it." There are hazards with that too.

Michael Sauder: That makes me think about another question. I wonder if people further up the hierarchy now have more confidence in their decision because of numbers. They actually think they have more access to quality than they used to think. Maybe they used to say: "well, that is up to the department". Now, they have a rubric that the numbers provide where they can feel more confident that they are actually seeing into those decisions. Again, that is an empirical question. The language of quantification is very interesting. In some cases, we have learned to speak in numbers. As departments, sometimes you have to use numbers even if your decisions are based on qualitative factors. When you write up why you want to make a decision, you use numbers to justify the qualitative judgment that you made even if that wasn't the basis of it. You know that those numbers communicate well up the ladder. So, if you can find numbers to justify your decision, it is better. The language of quantification is probably stronger than it ever has been before - part of this process that we have been talking about.

José Ossandón: Kreiner put it nicely in the sense that it is a kind of illusion of management. My sense is that the institution I work for has solved this traditionally, like a federal system in which each department keeps the right to define their own sense of quality. The current dean of research, I think, believes he is keeping this principle. To him, as far as I understand, each department can perfectly define their own criteria of quality, as long as they choose journals that are 


\section{Valuation Studies}

high in the rankings. The assumption is that while each discipline might have different journals, all disciplines must arrange journals in competitive rankings or lists.

\section{What would you tell to future practitioners?}

José Ossandón: The last question is basically another way of asking the same question that I have asked you several times. I have used your American Journal of Sociology paper many times in teaching. Here, students will learn that a tool like a ranking does not only more or less accurately measure what it is supposed to measure. They learn that rankings impact organizations, and in their exams, students will be expected to explain how your mechanisms of self-fulfilling prophecies and commensuration work. I think I have managed to explain it, and those students that get it manage to explain it back in the exams - so far so good. But, with your paper, and more generally when I teach sociological things to students of management, I always end up with a sense that what we do is create a split world for these poor students. On the one hand, it is what they learn in traditional management classes; where they learn about quantitative tools that will supposedly help them to successful attain business goals. Then, the social scientists, tell them, sorry, your tools don't measure what they are supposed to measure, and, even if they do, they create all sorts of new problems. But, in a way, what no one tells them is how to navigate the tension between these two messages which will probably be a crucial problem in their future careers.

I think, what we learn from your deans is that these are management tensions. One the one hand, tools that promise to manage more than they can, and on the other hand that these tools create all sorts of side effects. They work in this world and with knowledge of the tensions, but probably without the tools to integrate these two dimensions. The question is, then, what would you tell students of management? What could they or what would you like them to learn from your studies on the impact of rankings?

Michael Sauder: I guess the two things that come to mind are always at least an attempt to take a step back and be reflexive about what you are using the number for, or what the limitations of the number are. So, you have that sort of moment of "let's think about this" and not take it for granted. That would be a great thing. What is the number designed for? Am I using it in a way that is consistent with its design? Just to be reflexive and reflective about the numbers you use. The second point would be this idea that there are multiple ways of valuing things. One of our concerns, I think, about numbers is that they become the dominant way of evaluating things. To have people understand ... they are going to use numbers because they are so 
efficient and practical, but to at least try to think of other ways to value things and assess processes to complement the numbers that you have.

Wendy Espeland: One question that we raised in another context is something that managers can ask themselves, which is: what is important that is not being measured here? What are crucial aspects of management that we are not measuring? The term that gets used a lot in management is organizational culture. People talk about how difficult it is to change organizational culture, but how fundamental it is. So, one question you can ask is, okay, if organizational culture is so important to you, why is that not measured? Maybe you can measure it using some kind of survey. But what are the crucial aspects of the organization that you are directing that are not lending themselves to the numbers that are being circulated? So, morale ... there are many important values inside organizations that are not necessarily captured by numbers. So, reminding managers that they also need to attend to those, I think is one valuable thing to do.

José Ossandón: You would push them to be more like qualitative sociologists? [all laughing]

Wendy Espeland: At least to consider being mindful of, as Michael is suggesting, the limitations and not just the measures, but the limitations of what lends themselves to easily being measured, and how that compares with other things that are really important.

José Ossandón: Well, these were my questions. Last thing, are you planning to study things in relation to management in universities? What are you thinking to do, if I can ask?

Wendy Espeland: One thing that I am interested in is that we have departments in universities in the US that do what is called "institutional research". They are in charge of producing all the numbers, basically, that universities use. A lot of the numbers that they use have to do with surveys and student feedback. They also produce the numbers and overlook the numbers that are used for ranking purposes. So, I think that would be an interesting thing to research if one were allowed access to these kinds of departments.

José Ossandón: Are you developing this further, Mike?

Michael Sauder: I have a graduate student from South Korea, and he is very interested in studying rankings in South Korea. That has me 


\section{Valuation Studies}

thinking about these institutionalization processes that we have discussed. The numbers there are really taken for granted, and not questioned anymore. It moves to this new stage of what does it mean for quantification ... once quantification is kind of taking over, how do people manage that? How has it changed the power relations within the organization? How does it change how the university relies on the resource dependence situation with other institutions in the field?

José Ossandón: By the way, I could add that ended up in another taskforce, and it is about the CBS student evaluation system. This is another of these powerful numbers in universities. And I think it is quite interesting to me to follow the ways in which those who participate in this process think about these numbers, and how people who work in teaching and learning, they seem to be very reflexive about these things - maybe because people with a pedagogical background know a lot about the limitations and side effects of assessment systems. Well, but this is not to be developed now. Anything else that you want to say before we close?

Wendy Espeland: The main thing I want to say is thank you for allowing us to be part of this conversation.

Michael Sauder: Yes, thank you.

\section{References}

Beunza, Daniel. 2019. Taking the Floor: Models, Morals, and Management in a Wall Street Trading Room. Princeton, NJ: Princeton University Press.

Espeland, Wendy. N., and Michael. Sauder. 2007. "Rankings and Reactivity: How Public Measures Recreate Social Worlds.” American Journal of Sociology 113(1): 1-40.

Espeland, Wendy. N., and Michael. Sauder. 2016. Engines of Anxiety: Academic Rankings, Reputation, and Accountability. New York: Russell Sage Foundation.

Karpik, Lucien. 2010. The Economics of Singularities. Princeton, NJ: Princeton University Press.

Kreiner, Kristian. 2021. "Valuation Ecologies and Academic Governance." Valuation Studies this issue.

Lamont, Michèle. 2009. How Professors Think: Inside the Curious World of Academic Judgement. Harvard, MA: Harvard University Press.

March, James. G., and Johan P. Olsen. 2010. Rediscovering Institutions. New York: Simon and Schuster.

Miller, Peter, and Nikolas Rose. 1990. "Governing Economic Life.” Economy and Society 19(1): 1-31.

Musselin, Christine. 2018. "New Forms of Competition in Higher Education.” Socio-Economic Review 16(3): 657-683. 
Musselin, Christine. 2021. Evaluation and Merit-Based Increase in Academia: A Case Study in the First Person. Valuation Studies 8(2): 73-88.

Ossandón, José. 2021. (University) Management after Valuation Studies: Carving A Practice in between the Offended Native, the Anxious Scholar, and the Useless Practitioner. Valuation Studies 8(2): 61-72.

Stark, David. 2011. The Sense of Dissonance. Princeton, NJ: Princeton University Press

José Ossandón is Associate Professor in the Organization of Markets, Department of Organization, Copenhagen Business School. He specializes in economic sociology, social studies of finance, and social studies of markets. His current collaborative research efforts focus on two main areas, the work and techniques deployed in the organization of markets designed to deal with collective problems, and, on the different actors and practices involved in managing households' finance. He is co-editor-in-chief of Valuation Studies and senior editor of The Journal of Cultural Economy.

Wendy Espeland is Professor of Sociology at Northwestern University. She has published in the areas of organizations, culture, law, and science and technology studies, with an emphasis on understanding quantification as a formative social process. Her 2016 book, with Michael Sauder, Engines of Anxiety: Academic Rankings, Reputations, and Accountability examines how efforts to evaluate institutions reshape them.

Michael Sauder specializes in the sociology of organizations, theory, culture, and inequality. His recent research has appeared in American Journal of Sociology, American Sociological Review, and Administrative Science Quarterly. Sauder's 2016 book with Wendy Espeland, Engines of Anxiety: Educational Rankings, Reputation, and Accountability (Russell Sage Foundation), is the culmination of an extensive project examining the unintended consequences of accountability measures on the individuals, organizations, and fields that they assess. 